\title{
БИОИНДИКАЦИОННАЯ ОЦЕНКА ВЛИЯНИЯ ЖЕЛЕЗНОДОРОЖНОГО ТРАНСПОРТА НА КАЧЕСТВО ОКРУЖАЮЩЕЙ СРЕДЫ
}

\section{BIOINDICATION ASSESSMENT \\ OF THE IMPACT OF RAILWAY TRANSPORT ON ENVIRONMENTAL QUALITY}

\section{A. Soskov \\ A. Streltsov}

Summary. An urgent problem of any modern industry is the formation of a large amount of waste: emissions into the air, waste water, solid industrial waste, and so on. This study is devoted to the use of bioindication assessment of the impact of railway transport on the quality of the environment. The material for assessing the ecological health of the terrestrial natural part of the Kaluga region was collected at 5 stationary points located in the area of the Tikhonova Pustyn railway station, Kaluga region, Russia. The assessment of the territory of the Kaluga region was carried out using the most technologically advanced, widespread, well-studied, methodically tested, convenient and proven species - silver birch. At 5 selected points, birch leaves were collected for the subsequent calculation of the coefficients of fluctuating asymmetry of birch leaves. It was revealed that the zones of the study area, even remote from industrial facilities, are subject to their destructive effects. It was found that the main factors that negatively affect the health of the environment in the study area are as follows: railways, road, anthropogenic factor.

Keywords: bioindication assessment, railways, highways, anthropogenic factors, environmental quality.
Сосков Александр Викторович

Аспирант, Калужский государственный университет им. К.Э. Циолковского alekcandr-angel@mail.ru

Стрельчов Алексей Борисович

Профессор, Калужский государственный университет им. К.Э. Циолковского

biomona@mail.ru

Аннотация. Актуальная проблема любой современной промышленности — образование большого количества отходов: выбросов в атмосферный воздух, сточных вод, твердых отходов производства и так далее. Данное исследование посвящено использованию биоиндикационной оценке влияния железнодорожного транспорта на качество окружающей среды. Материалом для оценки экологического здоровья наземной природной части территории Калужской области был собран в 5 стационарных точках, расположенных в районе железнодорожной станции Тихонова Пустынь Калужской области, Россия. Оценка территории Калужской области была проведена с использованием наиболее технологичного, распространенного, хорошо изученного, методически отработанного, удобного и зарекомендовавшего себя вида - березы повислой. В 5 выбранных точках были собраны листья березы для последующего вычисления коэффициентов флуктуирующей асимметрии листьев березы. Было выявлено, что зоны исследуемого района, даже отдаленные от промышленных объектов, подвергаются их губительному воздействию. Обнаружено, что основные факторы, негативно влияющие на здоровье среды в исследуемом районе, следующие: железнодорожные пути, автомобильная дорога, антропогенный фактор.

Ключевые слова: биоиндикационная оценка, железные дороги, автомобильные дороги, антропогенные факторы, качество окружающей среды.

Определение наличия в окружающей среде загрязнителя по состоянию определенных организмов, наиболее чувствительных к изменению экологической обстановки, представляет собой биоиндикационную оценку или биоиндикацию $[4,5]$.

Таким образом, биоиндикация - это оценка состояния среды с помощью живых объектов. С их помощью живых объектов может производиться оценка как абиотических факторов (температура, влажность, кислотность, соленость, содержание поллютантов и т.д.) так и биотических (благополучие организмов, их популяций и сообществ) [6].

По состоянию на данный момент более распространены физико-химические методы для оценки качества 
среды. Однако существуют 3 случая, когда биоиндикация незаменима:

1. Фактор не может быть измерен. Например, анализ пыльцы растений в Северной Америке за длительный период показал смену теплого влажного климата сухим прохладным и далее замену лесных сообществ на травяные. В другом случае остатки диатомовых водорослей (соотношение ацидофильных и базофильных видов) позволило утверждать, что в прошлом вода в озерах Швеции имела кислую реакцию по вполне естественным причинам.

2. Фактор трудно измерить. Некоторые пестициды быстро разлагаются, что не позволяют выявить их исходную концентрацию в почве. Например, инсектицид дельтаметрин активен лишь несколько часов после его распыления, в то время как его действие на фауну (жуков и пауков) прослеживается в течение нескольких недель.

3. Фактор легко измерить, но трудно интерпретировать. Данные о концепции в окружающей среде различных поллютантов (если их концентрация не запредельно высока) не содержат ответа на вопрос, насколько ситуация опасна для живой природы. Показатели предельно допустимой концепции (ПДК) различных веществ разработаны лишь для человека. Однако, очевидно, эти показатели не могут быть распространены на другие живые существа. Есть более чувствительные виды, и они могут оказаться ключевыми для поддержания экосистем $[7,8,9]$.

На сегодняшний день актуальной задачей является изучение оказываемого негативного влияния с целью его коррекции и минимизации. Для этого целесообразнее всего использовать биоиндикацию.

\section{Целью исслеАования}

Целью данного исследования является биоиндикационная оценка влияния железнодорожного транспорта на качество окружающей среды.

\section{Материалы и метолы}

Материалом для оценки экологического здоровья наземной природной части территории Калужской области был собран в 5 стационарных точках, расположенных в районе железнодорожной станции Тихонова Пустынь Калужской области, Россия. Оценка территории Калужской области была проведена с использованием наиболее технологичного, распространенного, хорошо изученного, методически отработанного, удобного и зарекомендовавшего себя вида - березы повислой [10]. В 5 выбранных точках были собраны листья березы для последующего вычисления коэффициентов флуктуирующей асимметрии листьев березы.

Сбор и обработка первичного биологического материала проводились в строгом соответствии с утвержденной на федеральном уровне методикой [11]. Оценка отклонений состояния организма от условий нормы по величине интегрального показателя стабильности развития для березы повислой.

Математическая обработка первичных замеров производилась на персональных компьютерах с использованием стандартных пакетов программ, дополненных авторской компьютерной программой «АsСa». Результаты математической обработки - коэффициенты флуктуирующей асимметрии. Расчеты коэффициента асимметрии проводились по формуле, которая используется при оценке величины асимметрии по нескольким размерным признакам как интегральный показатель: среднее относительное различие между сторонами на признак:

$$
\begin{gathered}
X_{a}=\frac{\sum_{i=1}^{k}\left(d_{l-r}\right)_{i}}{n k}, \text { где, } \\
d_{l-r}=\frac{d_{l}-d_{r}}{d_{l}+d_{r}}, k-\text { число признаков. }
\end{gathered}
$$

\section{Результаты}

Коэффициенты флуктуирующей асимметрии листьев березы составили 0.0555, 0.0524, 0.0485, 0.0516, 0.0559 для точек № 1, № 2, № 3, № 4, № 5 соответственно. Для наглядного соотнесения коэффициентов флуктуирующей асимметрии приведена таблица 1. Баллы характеризуют значение стабильности развития листьев березы: I - стабильность условной нормы, II - незначительное отклонение от нормы, III - средний уровень отклонения от нормы, IV - значительное отклонение, $\mathrm{V}$ - критическое состояние.

Согласно таблице 1, флуктуирующая асимметрия на изученной территории при минимальном значении коэффициента находится на среднем уровне отклонения от нормы. Это свидетельствует об ухудшении качества окружающей среды в районе объекта, станции железной дороги.

Максимальный коэффициент наблюдается в точке № 5, которая находится ближе остальных к станции Тихонова пустынь. Данному показателю присваивается балл V (критическое состояние). Коэффициенты точек № 1 и № 2 ниже, однако, близок к точке № 5 . В точке 
Таблица 1. Шкала оценки отклонений состояния организма от условий нормы по величине интегрального показателя стабильности развития для березы повислой

\begin{tabular}{|l|l|l|}
\hline Балл & Величина показателя стабильности развития & Полученные коэффициенты \\
\hline I & $<0,040$ (условная норма) & - \\
\hline II & $0,040-0,044$ & - \\
\hline III & $0,045-0,049$ & $0,0485-$ точка № 3 \\
\hline IV & $0,050-0,054$ & $\begin{array}{l}0,0524-\text { точка № 2, } \\
0,0516-\text { точка № 4 }\end{array}$ \\
\hline V & $>0,054$ (сильное, экстремальное отклонение) & $\begin{array}{l}0,0555-\text { точка № } 1, \\
0,0559-\text { точка № 5 }\end{array}$ \\
\hline
\end{tabular}

№ 1 также отмечается экстренное отклонение от нормы, однако точка № 2 имеет балл IV. Точка № 4 максимально отдалена от железнодорожных путей, однако приближена к автомобильной дороге. В данной точке наблюдается значительное отклонение от нормы, как и в точке № 2. Приближенность точки № 4 к автодороге делает коэффициент выше, чем в точке № 3, которая отдалена как от железной дороги, так и от автомобильной. Тем не менее, коэффициент в точке № 3 указывает на среднюю степень отклонения. То есть воздействие исследуемого промышленного объекта обширно и затрагивает те насаждения, которые находятся в относительно благоприятных зонах изучаемого района.

Показатели флуктуирующей асимметрии продемонстрировали ухудшение качества окружающей среды в точках, наиболее приближенных к железнодорожным путям и станции. Железнодорожное полотно влияет на окружающую среду посредством механических, химических и физических факторов: понижение качеств почвы, испускание различного рода излучения, разрушение ландшафта, ухудшение качества среды обитания живых организмов в целом. Поэтому коэффициент точек № 1 и № 2 довольно высок, демонстрирует значительное и критическое состояние развития листвы. Вытекает предположение: чем выше скопление железнодорожных путей и транспорта, тем выше вред для окружающей среды. Предположение подтверждается повышением коэффициента флуктуирующей асимметрии в точке № 5, которая наиболее близка к станции. Важно учитывать, что на качество среды в точке № 5 также оказывает совокупность антропогенных факторов, так как вблизи точки № 5 располагается дачный поселок. Показатели флуктуирующей асимметрии точек № 1 и № 2 существенно отличаются. Асимметрия в точке № 2 ниже, чем на самой станции, ей присвоен балл IV, в то время как коэффициент асимметрии точ- ки № 1 приближен к коэффициенту точки на станции и имеет балл V. Точки № 1 и № 2 имеют одинаковое окружение, единственным отличием является наличие другого дачного поселка с левой стороны от железнодорожных путей, т.е. около точки 1. Это еще раз подчеркивает негативное влияние не только промышленных объектов, но и деятельности человека.

Особого внимания заслуживает коэффициент асимметрии в точке № 4. Здесь наблюдается значительное отклонение развития листьев березы. Разница в коэффициентах точек № 3 и № 4 показывает, что при приближении к автомобильной дороге качество среды ухудшается. В ходе сравнения коэффициентов асимметрии в точках № 2 и № 4 выявлено, что качество среды около железнодорожного полотна и автомобильной дороги ухудшено почти в одинаковой степени. Обе зоны имеют оценку в VI балла по степени нарушения развития. Из этого следует, что железнодорожное полотно ухудшает качество среды равно, как и автодорога. Таким образом, такому «двойному» воздействию подвергаются насаждения в точке 5. Данный факт делает объяснимым повышенный коэффициент флуктуирующей асимметрии точки № 5, где наблюдается наибольшее скопление железнодорожных путей, что также может вызывать отклонения, усиливая негативное воздействие в разы. Антропогенный фактор становится завершающим в ряде воздействий на данную зону. Таким образом, критическое состояние развития листьев березы на территории точки № 5 обуславливается: близостью железнодорожного полотна, скоплением железнодорожных путей, близостью автомобильной дороги, близостью антропогенного воздействия.

Из этого вытекает предположение, что именно изза всестороннего воздействия на насаждения в точке № 5 качество окружающей среды находится в критиче- 
ском состоянии. Для понимания общей картины давайте сравним территорию вблизи станции с остальными точками по тем же самым факторам воздействия.

Таким образом, сразу в двух точках, № 1 и № 5, с экстремальным отклонением наблюдается фактор антропогенного воздействия. В то время как точкам № 2 и № 4, приближенным к промышленным объектам (железной и автомобильной дорогам), присвоен балл IV, т.е. они отклонены от нормы, но не достигают критического отклонения. Точки № 2 и № 4 находятся в относительном отдалении от антропогенного воздействия. Следовательно, деятельность человека и продукты его деятельности создают повышенный уровень асимметрии листьев в точках № 1 и № 5. Однако это не значит, что ухудшение качества среды вызвано только антропогенным воздействием. Широкий спектр негативных факторов создает общий негативный фон воздействия на среду в данном районе, ухудшая ее качество.

\section{Выво $\Delta \mathrm{b}$}

1. Из-за подверженности вредным воздействиям, здоровье среды в районе промышленных объектов ухудшено.

2. Зоны исследуемого района, даже отдаленные от промышленных объектов, подвергаются их губительному воздействию.

3. Основные факторы, негативно влияющие на здоровье среды в исследуемом районе, следующие: железнодорожные пути, автомобильная дорога, антропогенный фактор.

4. Населенные пункты, расположенные близко к дорогам, не обладают хорошим качеством среды.

\section{ЛИТЕРАТУРА}

1. Мясников Ю.Н. Экология и энергетика будущего // Труды Крыловского государственного научного центра. 2021. № 2 (396). URL: https://cyberleninka. ru/article/n/ekologiya-i-energetika-buduschego (дата обращения: 12.10.2021).

2. Кузнецов Е.В., Шакиров Р.Р. Биоиндикация загрязнения атмосферного воздуха с помощью лишайников // The Scientific Heritage. 2021. № 68-3. URL: https://cyberleninka.ru/article/n/bioindikatsiya-zagryazneniya-atmosfernogo-vozduha-s-pomoschyu-lishaynikov (дата обращения: 12.10.2021).

3. Федеральный закон Российской Федерации «0б охране окружающей среды» от 10.01.02. № 7-Ф3

4. Боголюбов А.Г. Столетие биометрии в России [Текст]. - Ботанический институт им. В.Л. Комарова РАН, г. Санкт-Петербург. Биология и Экология. 2002 г.

5. Биоиндикация, Ван Штраален [Электронный ресурс] — Режим доступа: http://biofile.ru/bio/22464.html, свободный.— Загл. С экрана.—Яз. рус, англ

6. Методические рекомендации по выполнению оценки качества среды по состоянию живых существ (оценка стабильности развития живых организмов по уровню асимметрии морфологических структур). (Утверждены Распоряжением МПР РФ от 16.10.2003 № 460-р). — М., 2003.— 24 с.

7. Захаров В.М., Стрельцов А.Б., Логинов А.А. и др. Рекогносцировочная оценка здоровья среды в модельных точках как основа для организации биомониторинга на территории Калужской области. / МФ «Биотест».—М., 1996. — 70 с.

8. Чижик Ольга Владимировна Биоиндикация территорий с повышенной радиоэкологической нагрузкой // Известия Самарского научного центра РАН. 2013. № 3-5. URL: https://cyberleninka.ru/article/n/bioindikatsiya-territoriy-s-povyshennoy-radioekologicheskoy-nagruzkoy (дата обращения: 12.10.2021).

9. Захаров В.М. Здоровье среды: методика оценки / Захаров В.М., Баранов А.С., Борисов В.И. и др.— М.: Центр экологической политики России, 2000.$68 \mathrm{c}$.

10. Евсеева А.А., Абрахманова 0.И. Мониторинг качества среды города Калуги методом биоиндикации при использовании Quercus Robur L // Ученые записки Крымского федерального университета имени В.И. Вернадского. Биология. Химия. 2021. № 2. URL: https://cyberleninka.ru/article/n/monitoringkachestva-sredy-goroda-kalugi-metodom-bioindikatsii-pri-ispolzovanii-quercus-robur-I (дата обращения: 12.10.2021).

11. Гелашвили Д.Б. Структурно-информационные показатели флуктуирующей асимметрии билатерально симметричных организмов / Д.Б. Гелашвили, Е.В. Чупрунов, Д.И. Иудин // Журн. общ. биол. — 2004. - Т. 65, № 4.— С. 941-949.

( С Сосков Александр Викторович ( alekcandr-angel@mail.ru ), Стрельцов Алексей Борисович ( biomona@mail.ru ). Журнал «Современная наука: актуальные проблемы теории и практики» 